\title{
A Gestão no Campo da Economia Solidária: Particularidades e Desafios
}

\author{
Carolina Andion
}

\section{Resumo}

A expansão acelerada do movimento associativo em todo o mundo, principalmente a partir da década de 80, tem feito com que os estudos sobre o tema se multipliquem; entretanto, no campo da administração, os estudos empíricos sobre as formas associativas ainda são pouco numerosos e, em geral, utilizam os pressupostos funcionalistas empregados na esfera privada, sem efetuar as adaptações necessárias ao entendimento das particularidades dessas organizações. A intensidade da ação desses grupos, assim como os papéis que eles assumem na sociedade contemporânea, fazem emergir a necessidade de reflexão mais profunda sobre suas formas de ação coletiva e sobre a sua gestão. Esse é o foco deste trabalho, que visa identificar princípios e práticas de gestão particulares às organizações da chamada Economia Solidária. Para tanto, concebeu -se um modelo de análise interdisciplinar baseado nas ciências sociais, o qual foi aplicado, por meio do método de observação participante, em duas organizações comunitárias, localizadas na cidade de Montreal. As conclusões desta pesquisa abrem perspectivas para a compreensão deste campo, trazendo contribuições teóricas e práticas para estudiosos e profissionais interessados no tema.

Palavras-chave: economia solidária; gestão; movimento associativo.

\section{Abstract}

The expansion of the associative movement, mainly from the decade of 80 , has multiply the interest of professionals and researchers on the theme. However, in the management field, empirical studies still few, and, in general, they use the concepts and instruments of private enterprises, without adaptations. The work of the "third sector" and the role that they assume in the contemporary societies, claim to a deeper reflection about management ways used in this field. This is the focus of this work that aims to identify the particularity of management practices and principles in organizations of Solidary Economy. For that, the author conceived an interdisciplinary analysis model and applies it, through the method of participant observation, in two communitarian organizations located in Montreal. The conclusions of this research open perspectives to the understanding the field, bringing new practical and theoretical contributions in the subject.

Key words: solidary economy; management; associative movement. 


\section{INTRODUÇÃO}

Este artigo apresenta os resultados de uma pesquisa conduzida por dois anos, na École des Hautes Études Commerciales de Montreal, a qual teve como objetivo central identificar as particularidades da gestão das organizações da economia solidária, entendidas ao mesmo tempo como organizações que internalizam uma preocupação com a solidariedade e propõem serviços de proximidade que visam à transformação social (LAVILLE, 1997).

A premissa que direcionou o estudo foi que a especificidade das organizações da chamada economia solidária pressupunha formas também particulares de interação dos seus membros e entre estes e o meio externo, assim como lógicas singulares de tratamento das atividades econômicas e técnicas. Tais práticas dariam forma a um estilo de gestão próprio dessas organizações.

Para a realização da pesquisa, a autora atuou como voluntária em duas organizações comunitárias situadas em Montreal e, por meio do método da observação participante, buscou identificar os traços singulares da sua gestão. Para verificar a premissa apresentada, optou-se por utilizar uma visão não funcionalista da gestão, concebendo um modelo de análise interdisciplinar que permitiu associar as diversas dimensões do fenômeno da gestão. Tal modelo, que será mais detalhado a seguir, serviu de referência para a realização do trabalho de campo, onde se buscou identificar, acima de tudo, as representações que os próprios atores envolvidos tinham a respeito dos princípios e práticas de gestão.

O trabalho de campo foi realizado em seis meses, onde a pesquisadora trabalhou nas entidades pesquisadas, envolvendo-se em atividades fim e nos seus processos de gestão: reuniões dos conselhos, reuniões de equipe, processo de planejamento, entre outros. Nas duas organizações a pesquisadora tinha papel definido, o que permitiu a inclusão, a aceitação e a integração nos grupos. Além das observações, foram feitas também entrevistas e analisados certos documentos.

A análise das evidências de pesquisa conduziu à construção do texto e às conclusões do trabalho que são apresentadas a seguir e pretendem contribuir para uma maior compreensão sobre a especificidade das formas de gestão nas organizações da economia solidária. 


\section{A Emergência da Economia Solidária e a Delimitação do seu Conceito}

A redefinição do papel do Estado enquanto agente regulador traz novos desafios para os processos de intervenção social nas sociedades contemporâneas, fazendo com que o controle das externalidades produzidas pelo sistema capitalista seja feito por novos mecanismos reguladores. Após a crise do modelo Fordista, o jogo das forças de mercado, amparado pela ação do Estado Providência, não tem conseguido produzir por si só soluções sustentáveis de desenvolvimento social (LIPIETZ, 1991).

A redefinição do papel do Estado foi acompanhada nas últimas décadas por uma mobilidade dos agentes sociais em todos os níveis. Giddens (1996) descreve este processo como a emergência de uma democracia dialógica que provém não do triunfo das instituições democráticas tradicionais, mas especialmente do fortalecimento de uma sociedade civil ativa. O fato de a solidariedade administrativa, promovida pelo Estado do Bem-Estar Social, ter cedido lugar para a participação da sociedade civil nos espaços públicos reconfigura a noção de política na atualidade. Essa reconfiguração não significa, segundo Giddens, um desinteresse geral pelos temas coletivos como solidariedade e democracia, mas a concepção de novas formas de se chegar a eles.

Esse novo equilíbrio de forças políticas e sociais, que Giddens denomina de terceira via, é justamente uma renovação da cultura cívica que vem ocorrendo em diversos países. Conforme apontam Cohen e Arato (1997), retomando Max Weber, a sociedade moderna está vivendo a era do desencantamento. As utopias políticas tradicionais como o marxismo, o anarquismo, a radical democracia e o próprio liberalismo ortodoxo perderam o seu potencial de mobilização. Para eles, a renovação do discurso da sociedade civil lança novas esperanças, no que se refere à política. Sua emergência indica um novo tipo de utopia, que eles denominam de auto-limitação, uma utopia que inclui diversidade de formas complementares de democracia e um complexo conjunto de direitos civis, sociais e políticos, que devem ser compatíveis com a diferenciação moderna da sociedade.

Baseados nestas concepções, eles definem sociedade civil como sendo:

"A esfera de interação social entre economia e Estado, composta principalmente de uma esfera íntima (especialmente a família), a esfera das associações (especialmente aquelas voluntárias), movimentos sociais e formas de comunicação pública. A sociedade civil moderna é criada através de formas de auto-constituição e auto-mobilização. Ela é institucionalizada e generalizada, por meio das leis e especialmente dos 
direitos subjetivos que estabilizam a diferenciação social. As dimensões de auto-criação e de institucionalização podem existir separadamente, mas ambas são necessárias para a reprodução da sociedade civil” (COHEN; ARATO, 1997: ix, tradução livre).

O fortalecimento da sociedade civil é um fenômeno central para a compreensão do surgimento e da legitimação da chamada economia solidária em diferentes países. Neste contexto de profundas ressignificações políticas, mas também econômicas e sociais, emergem com toda a força as organizações "solidárias" em diferentes regiões do mundo.

Estas organizações atuam em setores diversos, tais como saúde, educação, transporte, lazer, desenvolvimento urbano, proteção do meio-ambiente, serviços domésticos, alimentação, defesa de direitos, etc. e têm como objetivo comum a promoção do interesse geral. Podem assumir também formas jurídicas e nomenclaturas diferenciadas, já que seu surgimento está ligado à formação institucional e à dinâmica presente em cada sociedade.

De fato, tais iniciativas têm por base a ação local inserida na comunidade, que é aqui compreendida como partilha de um mesmo território (espaço) ou como pertencimento a uma rede de relações comuns (DOUCET; FAVREAU, 1991). Assim, a economia solidária assume formas de expressão flexíveis, que variam em função das estruturas legais dominantes, da organização social e dos diferentes backgrounds culturais, históricos e políticos presentes em cada região (DÉFOURNY, 1992).

Parece extremamente difícil ou até impossível dar uma definição universal e minuciosa para a ação das organizações da sociedade civil na área social. O que se percebe, entretanto, é que a sua atuação na economia mundial passa a ser cada vez mais reconhecida, tanto no que se refere à geração de empregos, quanto no impacto social das suas ações. Isso tem gerado interesse crescente por parte dos pesquisadores, fazendo surgir novas correntes que interpretam o fenômeno.

No Brasil, uma das correntes mais influentes é a do terceiro setor, termo freqüentemente utilizado para caracterizar as organizações que atuam no domínio social (FERNANDES, 1994; FISHER; FALCONER, 1998; SALAMON, 1998). Originário dos países anglo-saxões, o conceito de terceiro setor refere-se à natureza das organizações que não pertencem ao aparelho burocrático do Estado nem ao conjunto das empresas privadas e demais instituições que compõem a economia de mercado; portanto cabe nesta definição um conjunto vasto de organizações que vão desde as Ongs, passando pelas fundações empresarias e institutos e incluindo também as organizações populares, oriundas de iniciativas das comunidades, as cooperativas de crédito e os organismos internacionais de cooperação, que atuam como parceiros dos organismos locais e financiam inúmeros projetos no país. 
Pode-se perceber que dentro da definição de terceiro setor se encaixam organizações que possuem características, papéis e formas institucionais completamente diferenciadas, o que nos leva a questionar se efetivamente tais organizações podem ser classificadas em um único grupo. Por este motivo, não adotaremos neste trabalho a definição tradicional de terceiro setor e gostaríamos, antes de expor o corpo da nossa pesquisa, de propor uma diferenciação que pode fornecer algumas pistas para o estabelecimento de uma tipologia das organizações que atuam na esfera social.

Inspirando-se na noção de economia substantiva, definida por Karl Polanyi (1975), e nos conceitos de mundo do sistema e de mundo da vida, estabelecidos por Jürgen Habermas (1989), dividimos as organizações que atuam no campo social em três grupos, tendo por base seus princípios de regulação e seus modos de ação particulares. Tal classificação é resumida no Quadro 1 abaixo.

\section{Quadro 1: As Organizações que Atuam no Campo Social e suas Interfaces ${ }^{(1)}$}

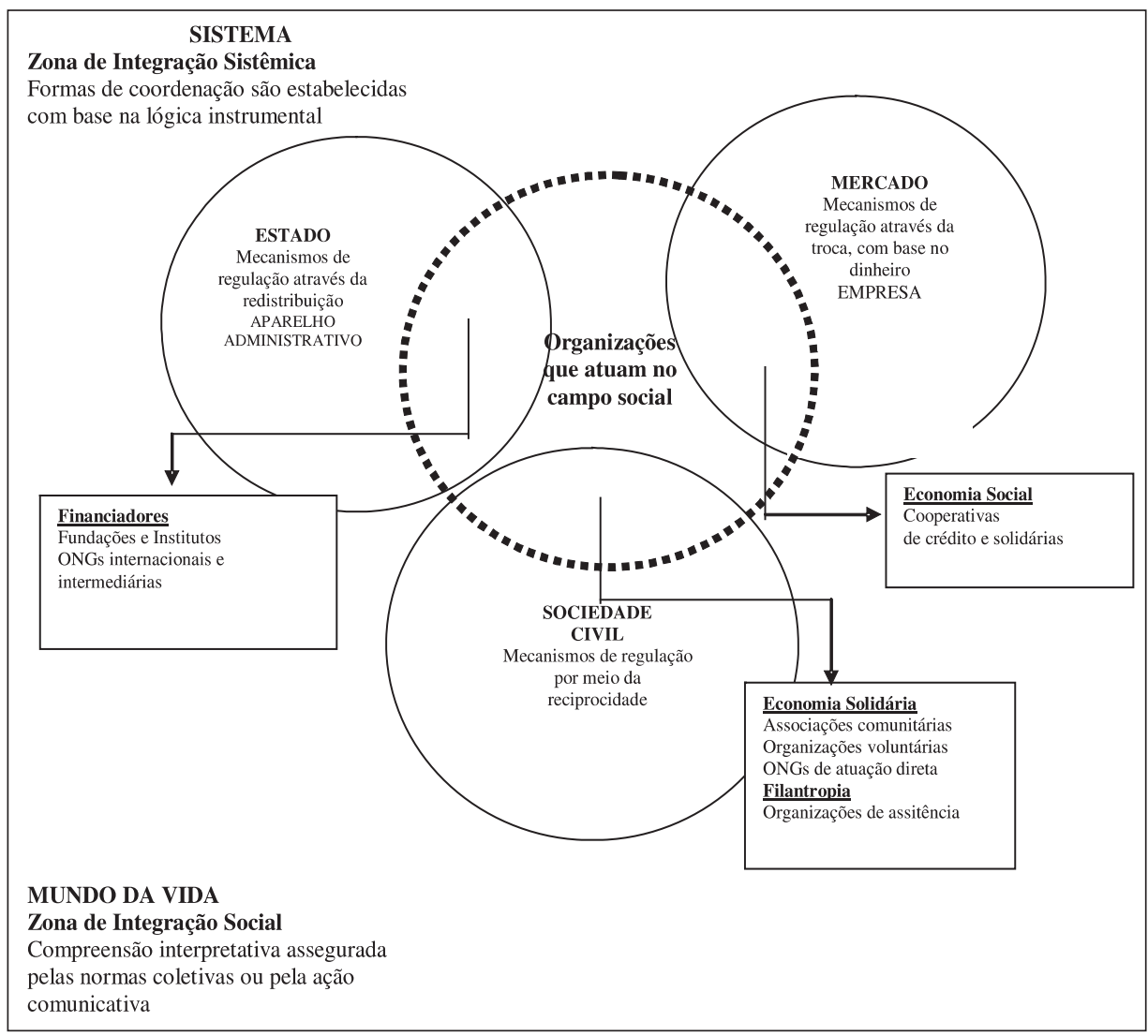

RAC, v. 9, n. 1, Jan./Mar. 2005 
No primeiro grupo, aqui denominado Economia Social, se encaixam organizações que têm uma forma de regulação com base na troca mercantil, aproximando-se mais da esfera do mercado. Essas organizações têm como função a produção de bens e serviços, visando responder às necessidades dos seus membros, tais como: as cooperativas e as mutuais de crédito e as cooperativas solidárias. Elas têm fins de lucro, mas este lucro é redistribuído entre seus membros proporcionalmente. Já no segundo grupo, aqui denominado Financiadores, agrupam-se os institutos, as fundações empresariais e públicas, as Ongs internacionais ou ainda as Ongs intermediárias entre os financiadores e a comunidade, que não operacionalizam diretamente programas e/ou projetos sociais. Essas organizações têm como princípio de regulação a redistribuição de recursos, públicos ou privados, visando ao bem comum. Neste sentido, seu papel se aproxima do papel do Estado, pois atuam como centros redistribuidores de recursos, com vistas a diminuir as desigualdades sociais. No terceiro grupo, se enquadram as organizações criadas a partir de uma mobilização da sociedade civil $^{(2)}$ e que não possuem fins lucrativos, tais como: as organizações da economia solidária (associações comunitárias, organizações voluntárias, Ongs de atuação social direta etc.) e as organizações filantrópicas. Neste grupo predominam formas de regulação baseadas na reciprocidade, tais como o dom e o voluntariado que, por sua vez, são indissociáveis das relações pessoais presentes na esfera comunitária.

Para entender o funcionamento das organizações que atuam no campo social, é importante ter em mente esta diferenciação, percebendo que algumas delas estarão mais em interface com o Estado ou com o mercado e, por isso, sua forma de funcionamento estará mais próxima do mundo do sistema, regulado pela lógica instrumental. Já outras terão maior inserção na esfera da sociedade civil, prevalecendo nestes casos as relações de proximidade, em que a lógica comunicacional está mais presente (HABERMAS, 1989). Entretanto é importante ressaltar que, na prática, esta classificação não é estanque. As organizações que atuam no campo social estão em constante interação e suas lógicas se interpenetram, se confrontam e se misturam, prevalecendo uma sobre as outras, em algumas situações, ou negociando entre si, em outros momentos.

Portanto, para os fins deste trabalho, estaremos enfocando apenas uma parte do conjunto retratado acima, formada pelas organizações da economia solidária. Tais organizações podem assumir configurações diferenciadas, mas todas elas surgem e se desenvolvem a partir da iniciativa da sociedade civil organizada. A pluralidade do fenômeno não deve ser negligenciada, pois dela advém a sua riqueza; mas considerando o resultado de pesquisas realizadas por vários autores ${ }^{(3)}$, em diferentes países, pode-se delinear algumas características comuns a este tipo de organização:

. Elas têm em geral papel social, que provém de um projeto definido. A criação de uma organização deste tipo está sempre ligada a alguma problemática precisa, conseqüência de demanda social. Desta forma, a riqueza coletiva, gerada por 
este tipo de organização, não se mede somente pelos produtos e serviços que ela gera, e sim pela sua contribuição à sociedade ou a coletivo mais restrito.

- Atuando como vetores para a realização de projetos sociais, estas iniciativas são caracterizadas como espaços enraizados na esfera pública, pois elas exprimem a capacidade dos cidadãos de agir para transformar a realidade em que vivem. Os membros de tais organizações, em geral, não são ligados por laços de sangue ou parentesco e provém de diferentes camadas sociais. Na sua interação cotidiana, estes atores negociam permanentemente para promover uma ação coletiva que vise ao interesse geral. Desta forma, operam a transição entre a esfera privada e a esfera pública, constituindo-se em comunidades políticas locais.

- A proximidade entre os indivíduos e a reciprocidade entre eles também redefinem as relações econômicas, presentes neste tipo de organização. É possível perceber a participação dos diferentes atores, assalariados ou voluntários, gestores e usuários, atuando coletivamente na gestão destes grupos e participando na concepção da oferta e da demanda dos bens e serviços. Esta participação permite um estabelecimento conjunto de preço e qualidade, visando, em muitos casos, à ampliação do acesso aos bens e serviços produzidos.

A diferenciação no preço e as formas de gestão financeira são baseadas numa hibridação de diferentes fontes de financiamento. Os recursos mercantis, provenientes da venda de bens e serviços; os recursos não mercantis, proveniente do financiamento do Estado e de outras agências financiadoras; e os recursos não-monetários, provenientes do voluntariado e dos dons recebidos, se combinam, permitindo maior flexibilidade e a continuidade dessas organizações ao longo do tempo.

Em síntese, os estudos realizados sobre as organizações da economia solidária mostram que sua principal diferenciação reside no fato de atuarem ao mesmo tempo como intermediárias e articuladoras de três esferas: a social, a política e a econômica. Desta maneira, essas organizações assumem, ao mesmo tempo, funções de espaços produtivos, geradores de bens, serviços e empregos; de espaços de proximidade, geradores de socialização; e de espaços públicos, geradores de reflexão e de ações políticas. Estas características constituem o pano de fundo para compreensão dos princípios e práticas de gestão aplicáveis a este tipo de organização.

\section{A Gestão em Organizações da Economia Solidária: Definição de um Modelo de Análise}

Apesar do dinamismo e da amplitude que o campo da economia solidária assume 
hoje, em diferentes países do mundo, a gestão das organizações que dele fazem parte ainda é tema pouco explorado, seja por causa dos preconceitos ideológicos existentes, seja por causa da falta de fundamentação teórica adaptada à natureza destas organizações. A administração sempre foi, desde os seus primórdios, concebida como ciência originária da esfera "formal” da economia e destinada ao estudo das organizações que compõem esta esfera. Assim, a ciência econômica tradicional e as principais teorias das organizações deixaram de enfocar, em suas pesquisas, as organizações que, de certa maneira, se colocavam à margem da esfera institucionalizada e cujo funcionamento não correspondia aos padrões estabelecidos nas teorias. Percebe-se que são poucos os estudos no campo da teoria das organizações (RAMOS, 1981; SERVA, 1996) que consideram as particularidades das organizações que atuam no campo social. A maioria dos autores de administração que estudam esse tipo de organização destituem de sentido as suas práticas internas, analisando-as a partir de uma concepção funcionalista, apoiada sobre os mesmos princípios e instrumentos aplicados às empresas públicas e privadas tradicionais.

A título de ilustração, destaca-se a corrente americana que trata da gestão de organismos sem fins lucrativos ${ }^{(4)}$, a qual exerce grande influência nos estudos realizados no campo do Terceiro Setor no Brasil. Nestes textos geralmente se recomenda aos leitores que as técnicas de gerenciamento, de marketing, de finanças, entre outras, utilizadas nas empresas privadas, sejam aplicadas nas organizações sem fins lucrativos, sem nenhuma preocupação em adaptá-las às particularidades destas últimas. Em alguns casos, estas particularidades são até consideradas como disfunções que devem ser equacionadas, de forma a facilitar a aplicação do management control process (ANTHONY; YOUNG, 1990).

Sem desconsiderar as contribuições das diferentes correntes da administração para a compreensão do funcionamento de qualquer tipo de organização, a proposta desta pesquisa é justamente de tratar as organizações da Economia Solidária na sua especificidade. Tendo por base uma abordagem complexa ${ }^{(5)}$ do fenômeno administrativo, consideramos as particularidades destas organizações não como acidentes contingenciais, mas como fatores essenciais para compreensão das suas formas de gestão.

Com base nestas considerações, foi concebido um modelo interdisciplinar de análise da gestão, que visa assegurar maior coerência à ontogênese dessas organizações. A teoria da ação comunicativa, elaborada por Jürgen Habermas (1986, 1987, 1989 e 1990), no campo da filosofia; a noção de economia substantiva proposta por Karl Polanyi $(1975,1983)$, no campo da antropologia econômica; a noção de autonomia social, difundida nas ciências sociais por Edgar Morin (1983, 1986), entre outros autores, e a teoria substantiva das organizações desenvolvida 
por Guerreiro Ramos (1981), no campo da teoria das organizações serviram de fundamentação teórica para a construção deste modelo.

Partindo do que existe em comum entre essas abordagens, pudemos identificar quatro dimensões interdependentes da gestão que compõem o modelo de análise.

A dimensão social refere-se à interação das pessoas dentro da organização. Nesta dimensão a análise teve como fundamento a teoria da ação comunicativa (HABERMAS, 1989), que fornece uma visão mais abrangente da racionalidade e das possibilidades de interação dos indivíduos. Segundo esta visão, os atos humanos e as razões destes atos não se inscrevem somente no mundo objetivo/ instrumental das coisas existentes, mas também no mundo da vida, partilhado intersubjetivamente pelas pessoas.

A dimensão econômica trata das formas de gestão dos recursos, financeiros e não financeiros, utilizadas na organização. Para análise desta dimensão foi considerada a noção de economia substantiva definida por Karl Polanyi (1975). Segundo esta noção, a economia é caracterizada como processo institucionalizado. A palavra processo reenvia à idéia de movimento e troca entre pessoas ou entre organizações. A palavra institucionalização qualifica este processo como estando inserido (embbeded) nas instituições econômicas e não econômicas da sociedade. Assim, Polanyi demonstra que existem outras fontes de regulação da economia, além do mercado, como a esfera doméstica, a redistribuição e a reciprocidade.

A dimensão ecológica considera as relações da organização com o meio ambiente externo, numa perspectiva de complementaridade entre as noções de autonomia e de dependência (MORIN, 1983). Nesta dimensão foram consideradas as múltiplas inter-relações das organizações pesquisadas com a comunidade local e com o sistema instituído, enfocando o choque de lógicas proveniente destes encontros. Além disso, buscou-se também identificar a ação política destas organizações, tanto no nível local como no plano institucional.

A dimensão organizacional e técnica aborda os aspectos referentes ao funcionamento interno das organizações e seus impactos sobre os indivíduos. Nessa dimensão foi considerada como base a teoria substantiva das organizações, defendida por Guerreiro Ramos, (1981). Segundo a lei de variedade de critérios, proposta por este autor, cada sistema social possui formas particulares de concepção dos seus processos organizacionais. Em particular, levamos em conta as diferentes fontes de produção de conhecimento na organização e o sentido atribuído às noções de eficácia e de trabalho, tendo como referência o trabalho de Serva (1998).

Apresentamos no Quadro 2 uma síntese, contendo todos os componentes do modelo de análise. 


\section{Breve Descrição das Organizações Pesquisadas}

Com base nos estudos já existentes sobre a economia solidária, foram escolhidas como objeto de pesquisa duas organizações sedeadas em Montreal que se enquadravam na maioria das características levantadas por tais estudos.

\section{Quadro 2: Modelo de Análise}

\begin{tabular}{|c|c|c|c|}
\hline DiMENSÕES & RUBRICAS & & VARIÁVEIS ANALISADAS \\
\hline SOCIAL & $\begin{array}{c}\text { Atores } \\
\text { Comunicação } \\
\text { Interação } \\
\text { Tomada de decisão }\end{array}$ & $\begin{array}{l}\Rightarrow \\
\Rightarrow\end{array}$ & $\begin{array}{c}\text { Membros; administradores; } \\
\text { coordenadores; trabalhadores; } \\
\text { voluntários } \\
\text { Meios } \\
\text { Finalidades } \\
\text { Mecanismos geradores } \\
\text { Relações entre os indivíduos e entre } \\
\text { os grupos } \\
\text { Instâncias de decisões } \\
\text { Critérios de validade }\end{array}$ \\
\hline ECÔNOMICA & $\begin{array}{l}\text { Recursos utilizados e suas aplicações } \\
\text { Construção da oferta e da demanda }\end{array}$ & $\Rightarrow$ & $\begin{array}{c}\text { Principais fontes de recursos } \\
\text { Despesas } \\
\text { Construção conjunta da oferta e da } \\
\text { demanda } \\
\text { Fixação de preços e definição de } \\
\text { critérios de qualidade }\end{array}$ \\
\hline ECÓLOGICA & $\begin{array}{l}\text { Interface com o mundo da vida } \\
\text { Interface com o mundo do sistema }\end{array}$ & $\begin{array}{l}\Rightarrow \\
\Rightarrow\end{array}$ & $\begin{array}{l}\text { Relação com a comunidade } \\
\text { Relação entre os membros } \\
\text { (partilha intersubjetiva) } \\
\text { Relação com o Estado } \\
\text { Relação com o mercado }\end{array}$ \\
\hline $\begin{array}{l}\text { ORGANIZACIONAL } \\
\text { E } \\
\text { TÉCNICA }\end{array}$ & $\begin{array}{l}\text { Processo Produtivo } \\
\text { Conhecimento e aprendizagem } \\
\text { Critérios de eficácia } \\
\text { Satisfação dos indivíduos no trabalho }\end{array}$ & $\Rightarrow$ & $\begin{array}{c}\text { Organização do processo produtivo } \\
\text { Recrutamento } \\
\text { Treinamento } \\
\text { Avaliação individual e avaliação de } \\
\text { impacto } \\
\text { Fatores geradores de satisfação } \\
\text { Valor atribuído ao trabalho } \\
\text { Iniciativa } \\
\text { Perspectiva futura }\end{array}$ \\
\hline
\end{tabular}


O Carrefour da Família é definido por seus membros como sendo "um centro de atividades que, por meio do prazer das crianças de 0 a 5 anos e dos seus pais, valoriza o respeito de cada pessoa, a cooperação e a partilha, apóia as famílias e estimula o desenvolvimento das crianças e a reflexão entre seus pais”. Para cumprir esta missão, desenvolve oficinas para crianças de 0 a 1 ano e de 0 a 3 anos (acompanhados de seus pais), oficinas para crianças de 3 a 5 anos, programa de integração para crianças com deficiências físicas ou mentais, grupos de discussão, oficinas com os pais, festas e excursões.

O Carrefour é uma creche diferente, criada em 1979 por um grupo de doze mães que eram vizinhas. Estas mulheres não trabalhavam, o que as privava de socialização, pois elas ficavam a maioria do tempo em casa. A partir desta necessidade, elas começaram a se reunir informalmente em suas casas e, em 1980, conseguiram um local num centro comunitário, cedido pela prefeitura. Desde então, o Carrefour se desenvolveu bastante, tendo sempre por base o trabalho voluntário das mães que geriam e operacionalizavam as atividades da creche. Em 1994, o Carrefour recebe uma subvenção do Governo Federal de cerca de U\$S 225.000,00 para três anos, referente ao PACE - Programa de Ação Comunitária para as Crianças. Para se ter uma idéia da mudança que isso representava, o montante anual recebido era sete vezes superior às receitas do Carrefour no ano anterior. Esta subvenção teve grande impacto sobre as diferentes dimensões da sua gestão, especialmente provocado pelos processos de crescimento e profissionalização da organização.

No final da pesquisa, em 1998, o Carrefour funcionava em dois centros comunitários, ampliando os serviços oferecidos e a programação das suas atividades. O programa PACE foi renovado por mais três anos e a organização contava com 18 trabalhadores (sendo 2 coordenadoras), 169 famílias membros, 215 crianças participando das oficinas e 87 voluntários.

\section{A Casa de Ajuda Mútua}

A Casa de Ajuda Mútua é um centro de ações comunitárias que desenvolve vários serviços e mantém redes de ajuda-mútua para pessoas de diferentes idades. Tem 22 anos de existência e foi fundada em 1976 por um grupo de religiosos e de militantes católicos de uma paróquia. Eles tinham como objetivo principal a criação de espaço em que as pessoas que não iam mais à igreja aos domingos pudessem encontrar-se. Segundo a coordenadora atual, que participou do processo de fundação, a idéia inicial foi: "de criar um projeto de casa [...] uma casa que estaria lá para acolher as pessoas de uma maneira incondicional, onde as pessoas pudessem tomar um café a qualquer hora do dia e também conversar com outras pessoas”. 
Com o passar do tempo, a ligação com a igreja foi diminuindo e a organização ampliou sua ação, tornando-se um projeto do bairro e não apenas da paróquia. Entretanto, a idéia de ser um espaço aberto, visando diminuir o isolamento social das pessoas e ajudá-las a mudar suas condições de vida se mantém. No final dessa pesquisa, a organização funcionava numa casa de dois andares com duas grandes salas, uma cozinha e vários quartos que serviam de escritório para os trabalhadores. Contava, em 1998, com 205 membros ativos, 100 voluntários e 6 trabalhadores, sendo uma coordenadora, que desenvolviam as seguintes atividades: (i) atendimento individual telefônico ou pessoal, apoiando as pessoas no preenchimento de formulários governamentais de ajuda social ou ainda informando sobre os serviços comunitários disponíveis; (ii) atendimento coletivo, por meio da realização uma vez por mês de um almoço comunitário e de encontros para discussão de temas da atualidade; (iii) oficinas de deveres e lições, que consistiam num serviço personalizado de reforço escolar, realizado por voluntários para crianças do primário de oito escolas do bairro; (iv) redes de ajuda mútua. A primeira, chamada la débrouille (o desabrochar ) consistia numa rede de pessoas com mais de 50 anos que se encontravam na casa uma vez por mês para discutir temas e para realizar ações. A segunda rede era a Cozinha Coletiva e compreendia 5 grupos de dez pessoas que cozinhavam juntas por um custo mínimo (pois a compra dos ingredientes é feita em conjunto e uma parte é subsidiada pelo governo) e depois dividiam as porções preparadas entre si. A cozinha coletiva tinha como objetivo promover uma alimentação mais saudável e econômica, por meio de uma experiência de socialização e de aprendizagem coletiva.

\section{Conclusões da Pesquisa}

Na análise dos dados, utilizamos como referência as rubricas definidas no modelo acima e tratamos cada uma das organizações separadamente. Em seguida, buscamos identificar aspectos comuns ou transversais às organizações e que expressassem evidências das particularidades de sua gestão.

\section{A Comunicação e o Espaço de Reflexão Interna}

Nos dois grupos de pesquisa identificamos a participação de diferentes atores na sua gestão: os membros, os voluntários, o Conselho de Administração, a coordenadora e os trabalhadores. Esses atores possuíam funções, interesses e lógicas diferentes e as suas visões a respeito da organização e de seus objetivos nem sempre eram comuns. 
Para se construir uma visão comum e um projeto social estabelecido coletivamente foi essencial, nos dois casos, a existência de espaços formais de comunicação que permitiram a manifestação e a negociação dessas lógicas particulares. Esta prática era um importante elemento de socialização, pois fazia emergir um mundo da vida comum nos grupos. Quando estes espaços existiam, podíamos perceber que havia uma negociação entre as diferentes lógicas, em busca de acordo necessário para a identificação do projeto social do grupo. Quando não se praticava esta negociação, as relações tendiam a se burocratizar e a comunicação passava a ser enquadrada em normas e procedimentos formais.

Isso aconteceu no Carrefour da Família, onde a ausência de espaços estruturados de interpretação entre os diferentes atores sobre a realidade do grupo levou a uma situação de separação entre os que participavam da gestão e os demais membros.

O que pudemos perceber neste caso foi que a comunicação operacional se sobrepôs à comunicação expressiva e os comportamentos funcionais começaram a prevalecer sobre as relações pessoa-pessoa. Isso poderia ser interpretado como um indício normal de crescimento e de profissionalização da organização; entretanto o enfraquecimento da partilha intersubjetiva dos diferentes grupos componentes do Carrefour teve muitos impactos negativos para a própria gestão da organização.

Observou-se esta repercussão, por exemplo, na integração dos novos trabalhadores e membros, que não se sentiam mais tão implicados com o projeto social do Carrefour. Houve diminuição da implicação voluntária, principalmente após 1994, quando o projeto passou a receber a subvenção do PACE, o que foi acompanhado também de desinteresse cada vez maior dos novos trabalhadores em relação às questões gerais da organização. Além disso, a falta de momentos de comunicação expressiva teve impacto também na própria definição do "bem comum” para o qual a organização atuava. Por falta de discussão mais ampla sobre o seu projeto social, vários membros do Carrefour da Família não possuíam uma visão clara do projeto social da instituição e agiam como simples “consumidores” dos serviços da creche.

Podemos constatar então que o exercício da ação comunicativa é processo chave na gestão das duas organizações estudadas, pois ele é gerador de integração entre os indivíduos e de interação entre eles. Entretanto, esta prática não é simples. Como verificamos na Casa de Ajuda Mútua, a existência de debate não pode ser confundida com a obtenção de acordo. Muitas vezes, o que se produzia era uma comunicação difusa, frágil e que colocava em xeque os suportes do grupo. As discussões podiam levar ao acordo, mas também fazer emergir o conflito. Lidar com esse processo, fazendo emergir as diferenças e buscando 
criar espaços de comunicação onde acordos são construídos, parece um dos desafios constantes da gestão de organizações da economia solidária que agem como espaços públicos de proximidade.

\section{Atividades Econômicas Inseridas nas Relações Sociais}

Verificamos durante a pesquisa que as atividades econômicas das organizações pesquisadas não se dissociavam das relações sociais existentes. Primeiramente, as organizações efetuavam uma hibridação de diferentes tipos de recursos provenientes de três fontes distintas: a redistribuição de recursos provenientes do Estado ou de agências de financiamento privadas; o mercado de recursos provenientes de trocas mercantis; e a reciprocidade do voluntariado e dons provenientes das relações interpessoais.

Esta mistura de formas de regulação distintas fornece uma característica particular às atividades econômicas realizadas por estas organizações. Além de sua composição se aproximar muito da economia substantiva, definida por Karl Polanyi (1975), percebemos que a forma de regulação econômica mais característica nas organizações da economia solidária é a reciprocidade. A reciprocidade pressupõe movimentos entre grupos simetricamente ordenados e está associada à prática de ajuda mútua que ocorre por meio dos dons e do voluntariado. Apesar de não contabilizadas nas organizações estudadas, identificamos que as práticas de reciprocidade eram fontes essenciais de recursos nessas organizações. No caso do Carrefour, por exemplo, em certo período da sua história, os recursos monetários eram muito escassos e o que manteve a creche funcionando foi o trabalho voluntário das mães. Contabilizando as horas de voluntariado nos dois casos estudados, tendo com referência o valor do salário mínimo no Canadá, chegamos a valores anuais de cerca de US\$ 20.000,00 no Carrefour e US\$ 68.000 na Casa de Ajuda Mútua.

As relações de proximidade influenciavam também a própria concepção dos serviços, especialmente a definição de sua qualidade e a fixação dos preços. A oferta e a demanda de bens e serviços eram definidas conjuntamente pelos voluntários, trabalhadores e usuários. Estes últimos participam ativamente da concepção do serviço, estabelecendo seus parâmetros de qualidade. Os preços, por sua vez, eram também definidos, levando em consideração as necessidades dos beneficiários. As taxas cobradas pelos serviços oferecidos nas duas organizações pesquisadas eram estabelecidas em função da renda dos usuários. Aqueles que ganhavam mais pagavam mais, aqueles que ganhavam menos, pagavam menos, chegando até a gratuidade. Esta forma de estabelecer o valor das coisas é definida por Godbout (1992) como valor de relacionamento, o qual é 
diferente do valor de troca e do valor de uso definidos comumente pela economia. Segundo este autor, o valor de relacionamento está condicionado à capacidade das coisas de expressar, de veicular e de nutrir as relações sociais. Este valor não é estabelecido por comparação com outras coisas, mas primeiramente em relação às pessoas.

Nos dois casos pesquisados, percebemos que a relação entre as pessoas assume mais importância do que a atividade econômica em si. Vários usuários nos asseveraram que eles achavam fundamental a personalização do serviço e a socialização que eles encontraram nestas organizações. A maioria não se sentia como cliente, pois sua fidelidade ao grupo provinha da partilha intersubjetiva (mundo da vida) e das relações pessoais construídas entre eles. Na criação do Carrefour, por exemplo, o fato de os membros serem mães com problemas de socialização as aproximou e permitiu uma troca entre elas. Já na Casa de Ajuda Mútua a exclusão social e econômica parecia ser a referência comum que encorajava a solidariedade entre os membros do grupo.

Tanto quanto a disponibilidade de meios financeiros, a reciprocidade e as relações de proximidade parecem constituir elementos essenciais para a perenidade das organizações do tipo solidário. Por isso, parece fundamental que os grupos da economia solidária conservem as práticas de reciprocidade, mantendo uma hibridação entre as diferentes formas de regulação. Se a troca mercantil prevalecer muito sobre as outras formas de regulação, a organização pode correr o risco de deixar de lado seu projeto social, em prol da lógica de mercado. Se a forma redistributiva se torna a regulação principal, a organização pode ficar dependente demais dos organismos financiadores, comprometendo a sua autonomia. Por fim, se a única forma de regulação for a reciprocidade, a organização também pode se fragilizar, correndo o risco de fechar suas portas por falta de recursos.

\section{Do Projeto Social à Finalidade Pública}

Percebemos que, apesar das organizações pesquisadas terem caráter formal privado, pois são associações civis sem fins lucrativos, elas apresentam finalidade pública, transcendendo o simples contrato entre pessoas físicas e englobando a busca de fins comuns, expressos em seu projeto social. A existência de um projeto coletivo que tem uma relação com valores sociais mais amplos constitui elemento de orientação e de legitimação das organizações; entretanto a constituição e a manutenção da coerência e da relevância deste projeto social ao longo do tempo não é uma tarefa simples. As organizações da economia solidária são formadas por uma diversidade de membros, cujas necessidades evoluem constantemente e 
não são necessariamente as mesmas. A função do projeto social é justamente a de fazer a transição das necessidades individuais para uma visão comum. Esse movimento depende de constante abertura para o diálogo entre os diferentes atores da organização.

Esta abertura para ouvir e incorporar as manifestações dos membros e da comunidade, no seio dos grupos comunitários, constitui a essência da sua caracterização como espaços públicos autônomos. Segundo Habermas (1992), estes espaços são lugares de formação de opiniões e de vontades políticas, que têm ressonância na organização social mais ampla. Para ele, esses espaços públicos plurais reenviam a um espaço público global, a um centro, que não constitui mais que uma projeção. Neste sentido, eles participam, cada um na sua medida, para a instituição pública do bem comum.

Os dois casos analisados nos mostraram que, para constituir um espaço público, a produção de bens e serviços não é suficiente. É necessário que a organização consiga produzir com a sua ação uma transformação social, interna e externamente. Internamente, isso ocorre por meio da apropriação do projeto social por parte de todos os atores envolvidos, especialmente os usuários, o que é crucial para a instauração de uma gestão interna mais democrática. Pode-se criar descompasso, se a organização promove uma contribuição extraordinária para a sociedade e internamente prevalecem relações de desconfiança, autoritarismo e exclusão entre os seus membros. Externamente, a transformação depende de uma ação da organização junto à sociedade mais ampla. É necessário, para tanto, que a organização atue como agente mobilizador da consciência cidadã de seus membros e da comunidade em que atua, não se preocupando somente com suas questões internas (corporativismo), mas enxergando o seu papel enquanto espaço público inserido numa coletividade mais ampla.

\section{As Manifestações do Mundo da Vida}

O mundo da vida é definido por Habermas $(1987,1989)$ como saber implícito que age como referência e código de interpretação em determinada comunidade de comunicação. Este saber de fundo é intersubjetivo, ou seja, partilhado pelos membros de um grupo, criando um sistema comum de interpretação que vai guiar a ação dos membros e criar predisposição à compreensão mútua.

Na nossa análise percebemos que o mundo da vida é elemento distintivo do funcionamento das organizações da economia solidária. A fidelidade dos membros a essas organizações vai muito além da compra de bens e serviços, aspecto determinante da fidelidade na maioria das empresas privadas. Para a maioria dos usuários, voluntários e mesmo trabalhadores pesquisados, a 
importância dos grupos nos quais eles participam reside não nas atividades propriamente ditas, mas nas relações de proximidade que se estabelecem entre as pessoas.

O mundo da vida e a intersubjetividade criada por ele parecem produzir socialização, coesão social e implicação das pessoas nestes grupos. Isso se observou, por exemplo, nas redes de ajuda mútua, no voluntariado e na implicação pessoal dos assalariados com o seu trabalho. As redes de ajuda mútua eram constituídas naturalmente entre os membros, independentemente da existência de um passado comum entre eles. O voluntariado estava também diretamente relacionado às relações de proximidade que se estabeleciam entre os voluntários e os beneficiários. As práticas de voluntariado tinham por base fatores motivacionais, grau de implicação e expectativas distintas dos padrões presentes nas relações salariais tradicionais e, por isso, era gerido de forma específica.

A atitude dos assalariados, por sua vez, era marcada por grande investimento pessoal no trabalho. Com base nas entrevistas realizadas, pudemos perceber que para essas pessoas o trabalho era fonte de satisfação e engajamento pessoal, contrariamente à visão mecanicista e impessoal do trabalho, apresentada pelas teorias tradicionais da administração.

Por outro lado, constatamos também que o mundo da vida se apresenta nas relações estabelecidas entre as organizações e a comunidade. A ênfase no local era ponto distintivo, principalmente da Casa de Ajuda Mútua, que era reconhecida no bairro e na cidade como uma referência em termos de liderança comunitária. Este enraizamento na comunidade se produzia na prática, mediante a participação efetiva da comunidade na organização e por alianças e parcerias com outras organizações locais. Estas últimas permitem uma ação conjunta sobre problemáticas comuns, gerando maior efetividade na prestação do serviço e na promoção de transformações sociais.

\section{A Interface com o Mundo do Sistema}

As organizações da economia solidária estão sempre em interface com outras esferas sociais, tais como o mercado e o Estado. Estas organizações podem ser definidas como sistemas abertos no sentido estabelecido por Edgar Morin (1983): sistemas que podem nutrir sua autonomia por meio da dependência em relação ao mundo exterior. A subvenção e o apoio recebidos do Estado e do mercado é que permitiam, em grande parte, a sobrevivência, tanto do Carrefour, quanto da Casa de Ajuda Mútua; mas essas relações algumas vezes se apresentavam como ameaças à autonomia destes grupos, na medida em que exista uma completa submissão das organizações aos imperativos do mundo do sistema. 
Sem negar a importância das relações com o mundo exterior na constituição da autonomia das organizações solidárias, queremos destacar os desafios que essas relações evocam. O principal deles advém do encontro de lógicas distintas. Como abordamos precedentemente, os organismos pesquisados são, em grande parte, baseados nos componentes do mundo da vida: relações pessoais, história comum, diálogo, reflexão coletiva, entre outros. O encontro desses elementos com os imperativos do mundo do sistema (poder, normas, controle, dinheiro etc.) constituem um desafio para as organizações da economia solidária. Este risco é inerente ao seu funcionamento, mas ele pode ser minimizado ou maximizado, em função do comportamento que a organização assume perante as instituições do sistema com as quais interage, principalmente os financiadores. Como destaca Lambert (1985), se a autonomia se acompanha de dependências inevitáveis, ela se torna mais autêntica, quando há assimilação, auto-apropriação das interdependências, ao invés de serem simplesmente obedecidas. Nos casos estudados, isso ocorria, quando as organizações buscavam influenciar as decisões políticas dos financiadores e compreender os desafios ligados ao financiamento, fazendo esforço para obter financiamentos coerentes com a sua missão e com a orientação das suas atividades. Esta reinterpretação das influências externas parece essencial para conservar a autonomia e a identidade das organizações da economia solidária, ao longo do tempo.

\section{Os Aspectos Técnicos e a Profissionalização}

As organizações da Economia Solidária, como qualquer outra organização produtiva, possuem exigências funcionais que estão presentes no cotidiano da sua gestão. Os imperativos da concorrência e os critérios definidos pelos financiadores exigem cada vez mais que as organizações do tipo comunitário se profissionalizem e isto se torna condição da sua perenidade. Nessa pesquisa ficou evidente que o desafio principal é o de como realizar esta profissionalização.

No Carrefour da Família, o processo de profissionalização tinha caráter funcional, levando a um distanciamento gradual entre os diferentes níveis da organização e a uma formalização das relações. As relações de proximidade estavam sendo gradualmente substituídas por relações burocráticas e isso começava a influenciar a qualidade do serviço e o grau de implicação das pessoas. Muitas mães se queixavam, por exemplo, das novas animadoras profissionais que tratavam seus filhos friamente e eram bem diferentes das mães voluntárias que atuavam antes como animadoras. Já na Casa de Ajuda Mútua, observamos certa resistência à especialização e à avaliação das atividades. Os aspectos relacionais eram sempre mais valorizados do que os aspectos técnicos. No caso da avaliação, por exemplo, a falta de parâmetros causava dificuldades na hora de 
comunicar com futuros financiadores, com o Conselho de Administração e com os próprios usuários, pois a organização não possuía referências para medir o desempenho nem dos indivíduos, nem do serviço prestado.

Percebemos, nos dois casos, que o processo de profissionalização não pode ser negligenciado, pois ele é elemento essencial para garantir a efetividade dos serviços prestados e a sua manutenção no tempo; porém esta profissionalização deve ser discutida e refletida, para que possa coabitar com os espaços do mundo da vida e não eliminá-los completamente. Como afirma Laville (1997), uma fração importante da validade associativa parece residir na sua capacidade de praticar uma profissionalização temperada. Muita especialização pode enrijecer e fragmentar a dinâmica social. Por outro lado, o excesso de voluntarismo pode tornar a gestão enfraquecida pela dificuldade de manter os voluntários e de promover as aprendizagens necessárias para garantir a credibilidade exterior dos serviços prestados.

\section{Considerações Finais}

Todas as particularidades definidas acima permitem traçar um retrato geral da gestão das organizações da economia solidária. Na dimensão social, percebemos que essas organizações precisam criar espaços de reflexão interna que sirvam aos seus atores como canais de expressão das diferenças e como espaços para a construção de acordos possíveis. Esse processo leva à criação de espaços públicos de proximidade no interior das organizações da economia solidária, o que causa impacto diretamente na sua gestão.

A criação desses espaços públicos pressupõe a interface de duas lógicas distintas: a do mundo da vida, que faz referência à intersubjetividade das pessoas e a do mundo do sistema, que está ligada à esfera institucional e às suas exigências instrumentais. Para tanto, a instauração de lugares para o debate é determinante, pois permite a redefinição do projeto social da organização e sua renovação, fazendo com que este acompanhe as mudanças nas necessidades e expectativas de seus membros.

No que se refere à dimensão econômica, o que particulariza a gestão nas organizações estudadas é a inserção das atividades econômicas nas relações sociais de proximidade. Este processo é caracterizado por uma não ruptura entre os fornecedores de serviço e os usuários. Além disso, a inserção do econômico no social pode ser observada pela hibridação de diversos meios de regulação 
(redistribuição, mercado e reciprocidade), cuja gestão em conjunto constitui fator relevante no funcionamento destas organizações.

A hibridação de lógicas está também presente, quando analisamos a dimensão técnica e os processos de profissionalização nas duas organizações. De fato, para evitar a tendência à burocratização das relações, o que as descaracterizaria, as organizações têm o desafio de ponderar os imperativos instrumentais imanentes a todo o processo de profissionalização e os elementos do mundo da vida intrínsecos aos grupos de tipo solidário. Isso ocorre também na sua interface com o meio externo, onde a autonomia dos grupos parece ser maior na medida em que eles reinterpretam e se apropriam das influências externas, reforçando assim sua própria identidade.

Podemos então concluir, afirmando que as organizações da economia solidária são espaços onde várias lógicas se confrontam permanentemente, por meio de uma dinâmica geradora de identidade. É principalmente na esfera da gestão que a confrontação destas lógicas é administrada, visando a gerar uma visão e ação comuns. Esta gestão cotidiana é tão complexa e dinâmica quanto a própria natureza destas organizações, pois ela é composta por uma série de desafios e questões singulares que não podem mais ser negligenciadas, nem pelos profissionais que atuam nestas organizações, nem pelas teorias que tratam desta temática.

\section{Artigo recebido em 14.05.2003. Aprovado em 24.05.2004.}

\section{Notas}

\footnotetext{
${ }^{1}$ Inspirado em SALES (1991). Privé, publique et société civile. Champs sociaux et structures de pouvoir. In: MAHEU e SALES (org.) La récomposition du politique. Montreal: Harmattan.

${ }^{2} \mathrm{O}$ conceito de sociedade civil, utilizado neste trabalho, tem por base a definição citada acima, estabelecida por Cohen e Arato (1997), acrescentada de duas contribuições referentes aos temas de produção, consumo e troca, levantadas por Keane (1988). Primeiramente a sociedade civil não é aqui interpretada como economicamente passiva, pois suas organizações também participam da esfera de mercado, vendendo bens e principalmente serviços. Como conseqüência, as organizações da sociedade civil não estão fora da economia e constituem uma das esferas da economia substantiva levantada por Polanyi (1975), tendo suas formas de regulação mais baseadas na reciprocidade.

${ }^{3}$ Em especial destacam-se os trabalhos dos pesquisadores do CRIDA - Centro de Pesquisa e Intervenção sobre a Democracia e Autonomia, criadores do conceito de Economia Solidária na França, inspirados nos aportes da sociologia econômica. Participam deste Centro entre outros: Jean-Louis Laville, Bernard Eme, Guy Roustang e Daniel Mothé. No Quebec, o movimento da Economia Solidária é traduzido pela corrente da Nova Economia Social e tem como principais
} 
autores Benoît Lévesque, Louis Favreau e Marie-Claire Malo. No Brasil, destacam-se os trabalho de Paul Singer, que recupera e difunde o conceito de Economia Solidária com um sentido bem distinto das escolas de língua francesa, apresentando-a como um "ressurgimento" do projeto de igualdade e democracia na esfera da produção proposto pelo movimento operário no século XIX, especialmente o movimento cooperativo de produção. Todos esses trabalhos focalizam mais os aspectos sociológicos e econômicos do fenômeno, abordando pouco a questão da gestão e do funcionamento dessas organizações.

${ }^{4}$ Ver GIES, L. David, OTT, David et SHAFRITZ M. J. The Nonprofit Organization - Essential Readings. Brooks/Cole Publishing Company. California: 1990 e CONNORS, T. D. The Nonprofit Handbook: management. John Willey and Sons inc., New York, second edition, 1997.

${ }^{5}$ Segundo MORIN, Edgar (1986), uma visão complexa dos fenômenos sociais deve considerar as seguintes noções: (i) perceber a singularidade, a temporalidade e a localidade dos fenômenos; (ii) reconhecer a unidade e ao mesmo tempo a diferença presente em cada fenômeno; (iii) considerar o evento, ou seja, o papel do acaso; (iv) fazer uma revisão do papel tradicional entre pesquisador e objeto de estudo, assim como da relação entre objeto e contexto; (v) repensar a sua própria racionalidade de base.

\section{Bibliografia}

\section{ANDION, C.}

La gestion des organisations de l'économie solidaire: deux études de cas à Montreal. 1998. Dissertação de Mestrado, Montreal, HEC.

ANTHONY, R. N.;

YOUNG, D.

Characteristics of nonprofit organizations. In: GIES, L. D.; OTT, S. J. ; SHAFRITZ, M. J. The nonprofit organization - essential readings. California: Brooks/Cole Publishing Company, 1990.

COHEN, J.;

ARATO, A.

Civil society and political theory. NewBaskerville: MIT Press, 1997.

\section{DEFOURNY,J.}

The Origins, Forms and Roles of a Third Major Sector. In: DEFOURNY, J.; CAMPOS J. L. M. Économie
Sociale: entre économie capitaliste et économie publique. Bruxelles: De Boeck Université, 1992.

\section{DOUCET, L.;}

FAVREAUL.

Théorie et pratiques en organisation communautaire. Québec: Presses de l’Université du Québec, 1991.

\section{EVERS, A.P.}

Allemagne: des expériences sans politique In: LAVILLE, J-L et al. Cohésion sociale et emploi.. Paris : Desclée de Brouwer, 1994.

FERNANDES, R. C.

Privado, porém público: o terceiro setor na América Latina. Rio de Janeiro, Civicus, 1994. 
FISCHER, R. M.;

FALCONER, A. P.

Desafios da parceria governo e terceiro setor. Revista de Administração USP. São Paulo, v. 33, n.1, jan./mar. 1998.

\section{GIDDENS,A.}

Para além da esquerda e da direita. São Paulo: UNESP, 1996.

\section{GODBOUT, J.}

L'esprit du don. Québec: Boreal, 1992.

\section{HABERMAS, J.}

Autonomy and solidarity: interviews with Jürgen Habermas. New York: Verso, 1986.

Teoría de la acción comunicativa. Tomes I et II, Madrid: Taurus, 1987.

Teoría de la acción comunicativa: complementos y estudios previos. Madrid: Catedra, 1989.

Écrits Politiques. Paris: Les éditions du Cerf, 1990.

L’espace public, 30 ans après, Quaderni. n. 18. Paris, automne, 1992.

KEANE, J.

Democracy and civil society. London: Verso, 1988.

\section{LIPIETZ, A.}

Audácia: uma alternativa para o século XXI. São Paulo, Nobel, 1991.

\section{MORIN, E.}

Peut-on concevoir une science de l'autonomie In: DUMOUCHEL, P.;
Dupuy, J-P. L'auto-organisation: de la physique au politique. Paris: Seuil, 1983.

Complexité et Organisation. In: AUDET, M.; MALOUIN, J-L(Dir), La production des connaissances scientifiques de l'administration. Québec: Les Presses de L’université Laval, 1986.

\section{LAMBERT, J-F.}

Séance plénière d'ouverture et discussions. In: CEPS/CRA. Autonomie sociale aujourd'hui: actes du colloque de Biviers. Grenoble, Presses Universitaires de Grenoble, 1985.

\section{LAVILLE, J-L}

L'association: une liberté propre à la démocratie e L'association: une organisation productive originale In: LAVILLE, J-L ; SAINSAULIEU, R. (Org.) Sociologie des associations. Paris, Desclée de Brouwer, 1997.

POLANYI, K.

L'économie en tant que procès institutionnalisé In: POLANYI, K ; ARENSBERG, C. Les systèmes économiques dans l'histoire et dans la théorie. Paris: Librarie Larousse, 1975.

La grande transformation: aux origines politiques et économiques de notre temps. Paris: Éditions Gallimard, 1983.

RAMOS, A. G.

The New Science of Organisations. Toronto: University of Toronto Press, 1981. 
ROCK, P.;

KLINEDINST, $\mathrm{M}$.

In search of the social economy in the United States: a proposal In: DEFOURNY, J. e CAMPOS, J. L. M. Économie Sociale: entre économie capitaliste et économie publique. Bruxelles: De Boeck Université, 1992.

SAINSAULIEU, R.

Associations et entreprises In: LAVILLE, J-L e SAINSAULIEU, R. (Dir.) Sociologie des associations.

Paris: Desclée Brouwer, 1997.
SALAMON, L.

A emergência do terceiro setor - uma revolução associativa global. Revista deAdministração da USP. São Paulo, v.33, n.1, jan./mar. 1998.

SERVA, M.

O Estado e as ONG's: uma parceria complexa Revista de Administração Pública. Rio de Janeiro: FGV, v. 31, n.6, nov/dez, 1997.

Racionalidade e organizações: o fênomeno das organizações substantivas. 1998. Tese de Doutorado

- Fundação Getúlio Vargas, São Paulo. 